\title{
VINCULACIONES ENTRE LA OBLIGACIÓN, EL CONTRATO, EL DERECHO REAL Y EL SISTEMA REGISTRAL. ESTUDIO COMPARATIVO ENTRE EL ORDENAMIENTO ARGENTINO Y EL PERUANO
}

\author{
Rodrigo Padilla ${ }^{1}$
}

\begin{abstract}
RESUMEN
El presente trabajo intentará vincular cuatro materias o asignaturas, a saber: el Derecho de las Obligaciones, los Contratos, los Derechos Reales e incluso el Derecho Registral. Los ordenamientos que serán tenidos en consideración van a ser el argentino y el peruano. Luego de pasar revista de las cuatro posibilidades referidas a los sistemas registrales, en este estudio se analizará la teoría del título y el modo, la inscripción registral, sus efectos, las distintas situaciones creadas desde la óptica del tríptico derecho a la posesión, de la posesión y de poseer y los conflictos que pueden generarse cuando varios acreedores contrataron con el mismo deudor. En fin, se concluye haciendo referencias al ordenamiento que rige en Perú desde el año 1984, el cual consagra un doble sistema: del consentimiento mitigado (estilo francés) para los bienes inmuebles; y del título y modo (estilo romano) para los muebles.
\end{abstract}

\section{PALABRAS CLAVES}

Obligaciones. Contratos. Derechos Reales. Derecho Registral.

\section{ABSTRACT}

This paper attempts to link four subjects: Law of Obligations, Contracts, Property, and Registration, focusing on the Argentinean and Peruvian legal systems. After briefly examining four possible registration systems, this paper analyzes the theory of 'title and form'; registration, its effects; the situations potentially arising out of the right of possession, possessing, and holding; and the disputes potentially arising when several creditors hire the same debtor. Finally, we conclude by referring to the legal system governing Peru since 1984, which enshrines a dual system: mitigated consent (French style) for immovable property; 'title and form' (Roman style) for movable assets.

\section{KEY WORDS}

Obligations. Contracts. Property Law. Registration Law.

Voy a tratar en esta oportunidad un tema que me resultó de tal atractivo que brindé dos conferencias sobre el particular ${ }^{2}$. Es que tiene la peculiaridad que vincula cuatro materias o asignaturas, a saber: el Derecho de las Obligaciones, los Contratos, los Derechos Reales, e incluso el Derecho Registral.

Por cierto que los ordenamientos que serán tenidos en consi- deración, como el propio título lo adelanta, van a ser el argentino y el peruano. Respecto del sistema argentino, es dable resaltar que el Código Civil vigente es del año 1871 (con una importantísima reforma producida en el año 1968 por medio de la ley 17.711) y el peruano es de 1984 (vale decir que no tendré presente los Códigos del año 1854 y 1936, salvo breves anotaciones sobre éstos).
Entonces, limitados a esos ordenamientos voy a intentar vincular las cuatro materias recién aludidas. Para lograr ese cometido me referiré siempre al contrato más típico e importante que puede existir: la compraventa. Pero no por lo que la misma representa en cuanto a la extensión de su articulado en el Código, frecuencia de uso por los particulares, etc.; sino por la vocación real

1 Profesor a cargo de cátedras universitarias tales como Derecho Privado II -Obligaciones-, Derecho Privado IV -Derechos Reales-, Derecho Registral y Director de Posgrado en Derecho Notarial en distintas Universidades de la Argentina. Autor de libros, capítulos y artículos referidos a estos temas jurídicos.

2 En la Universidad Femenina del Sagrado Corazón (UNIFÉ), en Lima; y en la Universidad César Vallejo, en Trujillo, Perú. 
que conlleva. Es que, como es sabido, este contrato genera dos obligaciones características: el pago del precio por parte del comprador y la entrega de la cosa -datio rei o traditiopor parte del vendedor.

Así, en general se puede sostener que del contrato de compraventa surge la obligación, por ejemplo, de dar una cosa "cierta o determinada". En tal caso el "vendedor" aún será dueño hasta que entregue la cosa (conf. surge del art. 577 del Cód. Civil para la Argenti$n^{3}$ y del art. 947 en materia de cosas muebles, para el Código peruano ${ }^{4}$; y el comprador sólo tendrá un derecho personal de exigir el cumplimiento. Sólo después de practicarse la datio rei se hará el traspaso del dominio mentado, adquiriendo recién el derecho real sobre ella (con la salvedad de la regla contenida en el art. 949 del Código de Perú ${ }^{5}$ ).

Es más, recién con la inscripción registral, si fuera bien inmueble o mueble registrable el tratado, adquirirá plena validez frente a todos, logrando la oponibilidad erga omnes. Pues bien, ahora explicaré un poco dicha proposición elemental para la correcta interpretación de las materias $o$ asignaturas que se interrelacionan.
¿CuÁNDO NACE EL DERECHO REAL? LAS CUATRO POSIBILIDADES EN MATERIA DE SISTEMAS REGISTRALES. TEORÍA DEL TÍTULO Y EL MODO

En el ordenamiento argentino se puede afirmar que para producir una mutación jurídico real, en materia inmobiliaria, hace falta un título suficiente (escritura pública), y un modo suficiente (traditio), requisitos que se complementan con la inscripción del título en el Registro para lograr plena oponibilidad del mentado derecho real inmobiliario.

En cambio, en el ordenamiento peruano "la sola obligación de enajenar un inmueble determinado hace al acreedor propietario de él", conforme reza el art. 949 del Cód. Civil; vale decir que no requiere la entrega de la cosa o traditio para constituir o generar el derecho real de dominio.

Mientras que en materia de cosas muebles ambos sistemas son similares (conf. arts. 577 Cód. Civ. argentino y 947 del Cód. Civ. de Perú) requiriendo para la adquisición de cosas muebles la pertinente traditio posesoria.

Como premisa de trabajo voy a seguir a mi querido maestro tucumano Fernando López de $Z_{\text {Zavalía }}^{6}$, quien enseñó que en esta materia se puede hablar de cuatro grandes posibilidades o sistemas que se denominan: consensualista; del título y el modo; del consensualismo mitigado; y del título y modo imperfecto.

Es decir que ante la pregunta de cuál es la causa fuente de la mutación real podemos responderla diciendo que existe sólo una causa o, por el contrario, que nos encontramos ante dos causas, dos hechos productores.

$\mathrm{Si}$ contestamos diciendo que existe un sólo hecho productor -una causa-, habremos tomado partido por el sistema consensualista. Ello implica que con el sólo consentimiento de las partes, la sola fuerza del contrato, basta para producir la mutación real. De esta forma no se establecen distingos visibles entre los derechos reales y personales.

En el extremo opuesto podemos responder al interrogante planteado diciendo que hacen falta dos causas, dos hechos productores. Al contestar así habremos abrazado a la teoría del título y el modo. Por tal se entiende que la causa mediata de la mutación real constituye su "título" (vg. compraventa); y la segunda causa, la inmediata, el “modo". Es decir que el

3 Artículo que reza "Antes de la tradición de la cosa, el acreedor no adquiere sobre ella ningún derecho real". Como se verá en el texto, esta disposición es fundamental, básica para comprender el genuino campo de los derechos reales, frente a los personales.

4 Dice la norma recién citada que "La transferencia de propiedad de una cosa mueble determinada se efectúa con la tradición a su acreedor, salvo disposición legal diferente".

5 Artículo que dice "La sola obligación de enajenar un inmueble determinado hace al acreedor propietario de él, salvo disposición legal diferente o pacto en contrario". Ya veremos la importancia de dicho precepto y su verdadera gravitación en este tema puesto que en ocasiones suele sobredimensionársela.

6 En Curso introductorio al Derecho Registral, Víctor P. de Zavalía Editor, Buenos Aires, 1983, págs. 234 y s.s. Ver también el trabajo que realiza el mismo autor en MOLINARIO, Alberto D. y otros, Curso de Derecho Registral Inmobiliario, Ediciones Pannedille S.A.E.C.I.F.I., Buenos Aires, 1971. 
sólo consentimiento de las partes no alcanza para producir esa mutación real, puesto que hace falta algo más, otro acto, que es el modo. Dicho modo puede ser tanto la tradición cuanto la inscripción registral. Remarcaré que el modo clásico fue la traditio.

Pero dije que entre tales sistemas opuestos existen otros dos intermedios. Pues para la tesis del consensualismo mitigado el solo consentimiento expresado en el contrato (título) es suficiente para producir la mutación real pero no para todos, sino respecto de muchos. Para que produzca efectos respecto de todos hace falta la "inscripción" en el Registro.

Por último, la teoría del título y el modo imperfecto establece que con el título más el modo -tradición- se produce la mutación real pero sólo frente a algunas personas. Para que produzca efectos respecto de todos hace falta la pertinente inscripción.

Así las cosas, fácil es sostener que Vélez Sársfield -codificador en Argentina- adoptó como sistema "general"7 la teoría del título y el modo en su versión pura, resultando el título, en las mutaciones inmobiliarias, la escritura pública y siendo el modo la traditio posesoria. Luego veremos qué pasó después de la reforma del año 1968 al artículo 2.505 del Código. Pero antes hagamos un repaso de la teoría mentada, la cual también es de aplicación en el sistema peruano, al menos respecto de cosas muebles (conf. art. 947 del Cód. Civ.).

Pues al respecto ha enseñado mi padre, René Padilla, que si bien la teoría del título y del modo es de origen romano, su desarrollo es posterior. Del Derecho romano debemos citar un texto de Justiniano que dice traditionibus et usucapionibus dominia rerum non nudis pactis transferentur (el dominio de las cosas se adquiere por la tradición o por la usucapión pero no por pactos desnudos) y otro de Paulus quien señaló que nunca la nuda tradición transfiere el dominio si no media una justa causa que le precede respecto de la que la tradición se hace. Además Gayo decía que la tradición o la entrega de la cosa debía estar fundada en algo que se podría llamar fundamento psicológico.

También merece destacarse al "Brachilogus Juris Civilis", obra anónima de un supuesto jurista de la época de Justiniano -metódicamente muy avanzada, y por ello sospechada- la cual señala que "el justo título es aquello que justifica y da razón de ser a la tradición" (vg. compraventa, permuta o donación).

Luego se aplica a estas proposiciones el esquema de la fi- losofía aristotélica, ello por influjo de los filósofos árabes y europeos, influenciados por Aristóteles. Así, dijeron que "la sustancia, la esencia, era el título, la existencia el modo". La esencia era aquello que daba el ser, que justificaba la existencia misma del negocio; que se manifestaba al exterior, que se exteriorizaba, y entonces recién tomaba existencia mediante la tradición. Entonces, al igual que me pregunté recién, me interrogo ahora ¿cuál es la causa eficiente del derecho real? Pues en forma parecida se respondía que la causa eficiente próxima es la tradición, pero la causa eficiente remota es el título.

Existen, por otro lado, ciertos aportes de la metafísica y la lógica. Respecto de la metafísica señaló Wolf que lo posible es el título y lo efectivo el modo. En cuanto a la lógica cabe destacar que se elaboró un silogismo cuya premisa mayor consistía en una facultad; su premisa menor en un hecho; y la conclusión el derecho adquirido. También hubo una visión religiosa del asunto. Así, se dijo que el título hacía las veces del alma; y el modo o tradición hacía las veces del cuerpo; y juntos formaban una sola unidad que constituía el derecho real o dominio sobre la cosa.

No voy a seguir complicando el tema con estos asuntos ${ }^{8}$, los cuales si bien son interesantes, me desvían del breve cami-

7 Dije como "sistema general", puesto que se sabe que para las hipotecas Vélez tomó otro camino. El artículo 3135 del Código es un fiel reflejo de la teoría del consensualismo mitigado. La razón de ser de dicha duplicidad radica en que la hipoteca simplemente no se manifiesta por la posesión, entonces mal podría la traditio servir como "modo" para la constitución de un derecho real que no necesita tradición, que no se exterioriza por la posesión.

8 Por cierto que merecen destacarse los aportes de Windscheid (teoría de la presuposición: se presupone que el acto traditorio está fundado o ha tenido por finalidad efectuar un pago, constituir un derecho real, u otras diversas finalidades. Es decir que verificada la tradición, sumada a la presuposición se lograba la adquisición del dominio) y de Savigny (quien ingeniosamente brinda el ejemplo de la limosna y se pregunta ¿dónde está el título o causa en este caso y si se transfiere el dominio al pobre? Contesta diciendo que sí, se transfiere el dominio y el justo título no es solamente el negocio que 
no a seguir. Solo resaltaré que siempre el modo implicaba algo "fáctico", un hecho, corporal, efectivo, o que se manifestaba al exterior y tomaba existencia, etc.

\section{EL TÍTULO Y EL MODO}

Desarrollada en forma harto simplificada la teoría del título y el modo, corresponde tratar a sus "componentes" por separado.

Primero hablaré del título, el cual tiene al menos tres acepciones: la primera en tanto que condición de una persona, calidad o situación.

Después se puede hacer mención al título instrumento (en sentido material), tal como se refiere, vg. el art. 1434 del Código de Vélez. Si se trata de alguna mutación real inmobiliaria estaríamos refiriéndonos a la escritura pública.

Por último también es dable hacer mención al título en sentido sustancial, lo cual equivale a "causa", en nuestro caso se trataría del negocio jurídico que sirve de soporte y fundamento al acto traditorio?.

En otro orden de cosas también la doctrina nos refiere a las clasificaciones de los títulos. En este sentido se habla de títulos gratuitos y onerosos; declarativos (vg. partición y transacción -con efectos retroactivos-) y traslativos, etc. Pues esta última clasificación me interesa. De hecho existen tres formas de hablar de títulos traslativos, 1) aquel que tiene potencialidad para que, acompañado con la tradición, haga nacer el dominio -vg. compraventa, permuta y donación, en Argentina-; 2) aquel título que forma parte o integra la tradición -contratos reales-; y 3 ) aquel que tiene por sí mismo potencialidad para hacer adquirir el derecho real, como la compraventa en Francia (conforme al artículo 1138 del Código napoleónico) o en el propio Perú referido a bienes inmuebles (conf. art. 949 del Código Civil).

Ahora me enfocaré en el segundo componente necesario para hacer nacer al derecho real (por lo menos en Argentina y en Perú respecto de cosas muebles). Me refiero al modo. En particular al "modo-traditio". Debo aclarar que tanto la tradición cuanto la inscripción registral pueden funcionar como "modo".

Y por modo entiendo a aquel recaudo legalmente establecido en cuya virtud se puede afirmar que desde que se lleva cabo existe recién un derecho real, por ello se le atribuye un carácter constitutivo, en su virtud se constituye recién el derecho real ${ }^{10}$.

Al respecto Vélez Sársfield fue contundente prescribiendo en el art. 577 que "Antes de la tradición de la cosa, el acreedor no adquiere sobre ella ningún derecho real"11. Este es un artículo clave, base, pieza maestra del sistema ideado por el codificador. Representa su hijo dilecto $^{12}$, si se quiere, lo cual implica tomar partido por la teoría del título y modo en su estado genuino, puro.

Por su parte, en el Perú debe tenerse en cuenta el art. 947 del Código Civil de 1984, el cual reza: "La transferencia de

ha creado el derecho personal que ha hecho nacer la obligación, sino que va a ser la intención misma de quien ha verificado la tradición). Ver en PADILLA, René A., Estudios de Derecho Civil y Registral Inmobiliario, Ediciones El Graduado, Tucumán, 1996, págs. 96 y s.s.

9 Ver PADILLA, René A., Estudios de Derecho Civil y Registral Inmobiliario, Ediciones El Graduado, Tucumán, 1996, págs. 99 y S.S.

10 PADILLA, René A., Estudios de Derecho Civil y Registral Inmobiliario, Ediciones El Graduado, Tucumán, 1996, pág. 110.

11 No tiene desperdicio la nota a dicha norma.

12 Al decir de LOPEZ DE ZAVALÍA, en Curso introductorio al Derecho Registral, Víctor P. de Zavalía Editor, Buenos Aires, 1983 , págs. 238 y s.s. Gráficamente enseñaba el brillante profesor Fernando López de Zavalía que el hijo “dilecto" era este sistema general en donde hacía falta título más tradición para hacer nacer al pertinente derecho real. Pero también Vélez tuvo desde su génesis un hijo "rebelde" representado por el sistema en materia de hipoteca, puesto que por disposición del art. 3.135 para este derecho real se necesitaba a los fines de la plena oponibilidad su inscripción en el Registro, creando así los Registros Hipotecarios -los cuales son históricamente los primeros en crearse, al menos en el ordenamiento hispano-. Sistema fiel a la teoría del consensualismo mitigado. Estos dos sistemas fueron considerados, usando la mentada analogía, "hijos de sangre", productos del Congreso de la Nación y con más exactitud, obras de Vélez. Pero con el correr del tiempo y atribuyéndose las Provincias prerrogativas vedadas, inconstitucionales, fueron engendrando otro "hijo", ya no del Congreso sino de las Legislaturas provinciales. Recién en el año 1968 este hijo fue "adoptado" por el Congreso y unido al hijo rebelde destronaron al dilecto que quedó hoy desplazado. En síntesis, el sistema actual en general responde a la teoría del título y el modo imperfecto y respecto de las hipotecas al consensualismo mitigado. Ver Curso introductorio al Derecho Registral, cit., pág. 249. 
propiedad de una cosa mueble determinada se efectúa con la tradición a su acreedor, salvo disposición legal diferente". Vale decir que en materia de cosas muebles ambos sistemas son similares: se adopta la teoría del título y modo en su versión clásica.

Lógicamente no indagaré sobre su naturaleza jurídica ${ }^{13}$, puesto que ello debe estudiarse en Derechos Reales. Por idéntica razón tampoco examinaré aquí la estructura interna del negocio traditorio ${ }^{14}$ ni cómo funciona la tradición en los contratos reales ${ }^{15}$, o si ésta es causal o abstracta $^{16}$. Pero sí es necesario que resalte que la traditio consiste en "actos materiales". En este sentido Vélez fue más que claro $^{17 .}$

\section{Por otro lado se debe remarcar} que existen casos en los cuales no hace falta realizar la mentada tradición para provocar la génesis del derecho real en cuestión. Se tratan de casos de tradiciones fictas, simbólicas, abreviadas, o situaciones en las cuales la traditio se ha materializado con anterioridad al título con vocación 'real'18. Pero debe quedar en claro que siempre se tratan de casos excepcionales, y por ello estimo que el requisito de la tradición -en nuestros ordenamientos- sigue siendo tan necesario hoy, cuanto lo era antaño. De hecho en las XXIII Jornadas Nacionales de Derecho Civil realizadas en Tucumán -Argentina- (29, 30 de septiembre y $1^{\circ}$ de octubre de 2011), el Despacho mayoritario de la Comisión 5 de Derechos Reales, propuso que "La protección de los intereses legítimos de los poseedores hace aconsejable la conservación de la tradición material como constitutiva del derecho real inmobiliario". Lo mismo quepa decir respecto del sistema de cosas muebles, materia donde los sistemas estudiados lucen semejantes -como ya resalté en varias ocasiones-.

13 En cuanto a su "naturaleza jurídica" existen autores que sostienen que se trata de un hecho jurídico. Sin embargo la mayoría entiende que es un acto jurídico. Para Perozzi es un acto unilateral porque se aposenta en la voluntad del tradens (otros autores piensan que se trata de dos actos unilaterales). Pero la gran mayoría proclama que en este acto jurídico hay una duplicidad de voluntades, dos personas: el tradens que hace la entrega y el accipiens que la recibe. Entonces la mayoría admite que la tradición es un acto jurídico bilateral incluso afirmando que se trata de un contrato, si se admite la tesis amplia. También se sostiene que la tradición no es más que el cumplimiento de una obligación preexistente, en tal sentido, la tradición implica un pago.

14 Analizando la estructura interna del negocio traditorio se advierte que la tradición está integrada o compuesta por dos elementos: un acuerdo real y un acto material de entrega. El acuerdo real es algo distinto al acuerdo ya prestado (título), por ejemplo si se ejecuta una compraventa (título) hará falta un nuevo acuerdo de las partes además del acto material de entrega de la cosa. De hecho si el acreedor se niega a recibir la cosa, no presta su consentimiento para realizar el acto material, el deudor puede desobligarse efectuando una "oferta real" (para quienes admiten esta figura), que no equivale a la tradición pero que lo desobligará igualmente.

15 En cuanto a la tradición en los contratos reales se puede afirmar que el título mismo es la tradición. En efecto, en el contrato real el título consiste en el acuerdo que forma parte del negocio traditorio. Y después -o simultáneamente- se verifica la entrega, se realiza el acto material de entrega. Este acuerdo real representa el consentimiento. Ver: PADILLA, René A., Estudios de Derecho Civil y Registral Inmobiliario, Ediciones El Graduado, Tucumán, 1996, págs. 111 y s.S.

16 Se habla de tradición causal, cuando se reconoce o postula que de una causa emana la tradición. Pero ciertos autores señalan que la tradición es abstracta, que goza de autonomía que la hace emancipar del título que le ha dado origen. Se dice que no es que la traditio no tenga causa, sino que ella es irrelevante, que no importa los vicios o defectos que pueda tener la causa, pues la tradición por sí misma tiene suficiente autonomía como para emanciparse de ella.

17 Recordé los artículos 2.378 y s.s. del Código Civil argentino. En tales disposiciones prescribe Vélez que la sola declaración no suple las formas legales -art. 2.378- y que la posesión de los inmuebles sólo puede adquirirse por la tradición hecha por actos materiales -art. 2.379-. Sin embargo se ha señalado, por ejemplo, que el "concepto de tradición merece una adecuación a los criterios que lo alejen de aquellas modalidades que requerían severamente actos materiales... la noción de tradición tiende a alejarse del rígido y sacramental acto de entrega voluntaria del tradens y la recepción también voluntaria del accipiens, cubierto ya de excepciones por vía de tradiciones simbólicas, especialmente en el derecho comercial y trasladada a la esfera civil con los proyectos de unificación (Proyecto de 1998 , arts. 1824 y 1826)", conf. MUSTO, Néstor Jorge, "La publicidad en el Código Civil y en la legislación actual”, en Homenaje a Dalmacio Vélez Sársfield, tomo III, Academia Nacional de Derecho y Ciencias Sociales de Córdoba, Córdoba, 2000, págs. 127 y s.s.

18 Situaciones tales como la traditio brevi manu: cuando la cosa es tenida a nombre del propietario, y éste -por un acto jurídico- le pasa el dominio de ella al que poseía en su nombre, conf. art. 2387 Cód. Civ. argentino (alude al caso en que estando en curso un contrato de locación una persona compra la propiedad en cuestión, cambiando su situación de inquilino a propietario); el constituto posesorio: alude al que transmitió la propiedad de la cosa y se constituye en poseedor a nombre del adquirente, conf. art. 2462, inc. 3, Cód. Civ. argentino (si después de realizar una venta, ese vendedor alquila esa misma propiedad); y la traditio per indicationem: cuando el locatario está ocupando el inmueble y el propietario se lo enajena a otro, bastando en este caso que se notifique a este 'tenedor' que en adelante en vez de poseer para el primer propietario lo hará para el segundo, art. 2387 del Cód. Civ. argentino (locación en curso: cambio de propietario). Ver: PADILLA, René A., Estudios de Derecho Civil..., ob. cit., págs. 106 y s.s. En el Código Civil de Perú debe tenerse en cuenta lo prescripto en el art. 902 que se refiere a la "sucesión de la tradición". 


\section{LA INSCRIPCIÓN REGISTRAL}

Dejando atrás -pero no olvidada- la teoría del título y el modo veremos cómo juega la inscripción en este tema. Qué participación tiene.

Respecto del ordenamiento argentino es dable subrayar que el sistema ideado por Vélez para la mutación jurídica real ha sido "modificado" por la ley 17.711 la cual agregó el requisito de la inscripción de las mentadas operaciones inmobiliarias en los Registros pertinentes para lograr pleno efectos respecto de terceros. También la ley 17.801 -que entró a regir en igual fecha que la 17.711- tiene repercusión directa en el sistema velezano, la cual tiene como base aquel modificado artículo 2.505.

Es cierto que mucho antes del año 1968 algunas Provincias habían creado sus propios Registros, pero se habían tomado atribuciones abiertamente inconstitucionales, puesto que tal prerrogativa pertenece al Congreso de la Nación ${ }^{19}$. Pero lo importante para resaltar aquí es cómo funciona ese nuevo requisito agregado al "modo", la inscripción del título en el Registro. Veamos entonces, someramente, los distintos efectos que puede tener la inscripción en los diversos ordenamientos jurídicos, cuestión también que corresponde su estudio profundo en las asignaturas de Derechos Reales y Derecho Registral. Pero voy a adelantar algo al respecto.

Pues bien, la inscripción puede tener carácter constitutivo (cuando el derecho real recién existe -o nace- cuando es registrado), declarativo (el acceso al registro declara una realidad extra-registral preexistente) $)^{20} 0$ mixto (vg. anteproyecto de Código Civil para la República del Paraguay de Luis Gásperi).

A su turno, dicha inscripción constitutiva puede ser extre- ma (como se estableció en Luxemburgo, Hamburgo, Sajonia, Lübeck, en donde la registración hacía nacer el derecho real con carácter de cosa juzgada, inmutable) o moderada (actual sistema alemán y el argentino en materia de automotores).

Por su parte la inscripción declarativa puede tener eficacia convalidante (España y Perú -conf. art. 2014 que consagra el principio de buena fe pública registral) o corroboradora (Francia y Argentina).

\section{Como se observa Argentina no} cuenta con un Registro saneatorio de vicios o convalidatorio. En este sentido es contundente el art. 4 de la ley 17.801 al determinar que "La inscripción no convalida el título nulo ni subsana los defectos de que adoleciere según las leyes". Dicho criterio fue reafirmado en las XXIII Jornadas Nacionales de Derecho Civil recién citadas, cuyo Despacho mayoritario pro-

19 Bien enseñan ANDORNO y MARCOLIN DE ANDORNO que apenas transcurrida una década de la sanción del Código Civil, comenzaron a crearse Registros en las distintas jurisdicciones locales, dada su utilidad y la necesidad de su implementación. El primero de ellos fue establecido en la Provincia de Buenos Aires a través de la ley 1276 del 21 de mayo de 1879. La propia Capital Federal también creó su organismo local por ley 1893 del 12 de noviembre de 1886. Dichas leyes sirvieron de modelo para la creación de los Registros de Catamarca (18/12/1896); Santa fe (20/06/1900); La Rioja (30/6/1900); Mendoza (18/9/1900); Santiago del Estero (18/9/1900); San Luis (30/11/1906); San Juan (27/7/1911); y Córdoba (30/4/1924). Se debe destacar, por otro lado, que en los primeros tiempos algunos de estos Registros estuvieron en manos de particulares, lo cual carece de fundamento pues el Estado se reserva para sí una tarea tan relevante como la registral inmobiliaria. También es sabido que una tacha de inconstitucionalidad se generó sobre dichos Registros provinciales. Al respecto la Corte Suprema nacional dictaminó la inconstitucionalidad del Registro de Catamarca (año 1935) y de Mendoza (1938). Sostuvo el alto Tribunal que tales leyes locales resultaban vulneratorias del art. 67, inc. 11, de la Constitución Nacional, pues el Código Civil es el único cuerpo que puede legislar acerca de la adquisición, transmisión y pérdida del dominio, estando vedado a las Provincias establecer otros requisitos fuera de los allí contemplados. Sin embargo los Registros siguieron funcionando debido a la utilidad que representaban. Esta situación llevó a Rafael Bielsa a decir esa frase célebre tan repetida de la "feliz anomalía de nuestra organización institucional" que se generó con esta situación. Como se sabe, recién con la ley 17.711 que modificó el artículo 2505 del Código de Vélez, se reparó dicha situación, "constitucionalizando" los Registros locales, tal como sostengo en el texto. Ver, ANDORNO, Luis O. - MARCOLIN DE ANDORNO, Marta, Ley nacional registral inmobiliaria. Ley 17.801. Comentada. Anotada, Hammurabi, Buenos Aires, 1989, pág. 34.

20 Para Llambías y Alterini “La inscripción es constitutiva cuando se la impone aun con referencia a las partes del negocio jurídico fuente de la transmisión, como también para la oponibilidad a los terceros desinteresados, y declarativa (no constitutiva) si la exigencia no alcanza ni a las partes del negocio jurídico, ni a los acreedores desinteresados, y se concreta a obrar como presupuesto de la oponibilidad a los terceros interesados y entre ellos el tercero registral", conf. LLAMBíAS, Jorge Joaquín - ALTERINI, Jorge H., Código Civil Anotado. Doctrina-jurisprudencia, Tomo IV-A, Derechos Reales, Abeledo Perrot, Buenos Aires, 1981, comentario art. 2505, pág. 289. Como se puede deducir fácilmente, al brindar los conceptos de inscripción constitutiva y declarativa los autores citados estaban pensando directamente en el art. 2505 del Código Civil argentino. 
puso que "El registro debe continuar cumpliendo su función de registración de títulos, con carácter meramente declarativo y no convalidante".

Así las cosas, como se dijo, hoy hace falta la inscripción en el Registro para obtener el "perfeccionamiento" del acto jurídico real. Es que después de reformado el art. 2.505 del Código Civil por ley 17.711 el sistema puro del título y el modo-traditio ha sufrido una importante modificación puesto que "La adquisición o trasmisión de derechos reales sobre inmuebles solamente se juzgará perfeccionada mediante la inscripción de los respectivos títulos en los registros inmobiliarios de la jurisdicción que corresponda. Esas adquisiciones o trasmisiones no serán oponibles a terceros mientras no estén registradas"21.

Merece destacarse, otra vez, que por medio de este artículo (complementado por la ley 17.801 , que lo tiene como piedra de toque) se "constitucionalizaron" todos los sistemas re- gistrales provinciales al requerir como requisito general, en todo el país, la inscripción del título en el Registro pertinente.

Claro que esta nueva norma es muy rica en interrogantes siendo uno de éstos el tema de la oponibilidad frente a terceros. $Y$ puesto que no puedo hacer en este lugar un análisis profundo de la cuestión, sólo resaltaré lo esencial desde mi parecer.

Y si el sistema registral argentino es declarativo -y corroborador-, como se dijo, la inscripción mentada sólo hace falta para el "perfeccionamiento" de un acto que ya existe entre las partes. Y no tan sólo entre las partes. También existe y no es necesaria la inscripción frente a los herederos de las partes, el escribano y los testigos (conf. arts. 20 ley 17.801 y 3.135 del Código Civil para hipotecas). Amén de ello, remarcaré que también será oponible a los terceros en general, simples terceros integrantes de la comunidad, aquellos terceros "desinteresados" (o poenitus extranei). Es que someramente debo dejar en claro qué se entiende por "terceros".

Pues según mi óptica el requisito de la inscripción es necesario para obtener oponibilidad frente a los terceros "interesados". $Y$ son terceros interesados quienes "por contar con un interés legítimo podrían invocar la inoponibilidad del derecho real no inscripto"22. Para los otros terceros no hace falta la inscripción puesto que no sufrirán perjuicio alguno en sus derechos.

En esta línea ha señalado López de Zavalía que "tercero" para los fines del art. 2.505 es quien no es parte "sustancial" y se puede ver perjudicado en sus derechos, de allí su "interés" y la necesidad de la mentada inscripción ${ }^{23}$. René Padilla, mi padre, también concluye que el tercero en cuestión, para quien hace falta la inscripción sino hará valer la "inoponibilidad" del acto, se trata de un "tercero registral" (aquel que requiere que haya inscripto el derecho que pretende esgrimir) ${ }^{24}$. Por cierto que la doctrina mayoritaria exige o pregona la "buena

21 El antecedente inmediato de dicho artículo reformado por Ley 17.711 debemos buscarlo en el III Congreso Nacional de Derecho Civil (Córdoba, 1961), específicamente en la ponencia de Julio I. Lezana, sobre cuya base se aprobó esta recomendación "La tradición requerida para la adquisición o transmisión de derechos reales sobre inmuebles, solamente se juzgará perfeccionada mediante la inscripción de los respectivos títulos en los registros inmobiliarios de la jurisdicción que corresponda y, en todos los demás casos, esas adquisiciones o transmisiones no serán oponibles a terceros mientras no estén registradas. En los casos de transmisión hereditaria, la inscripción tendrá efectos retroactivos al día del fallecimiento del causante". Por otro lado, es de amplio conocimiento que la Ley 17.801 (basada en el proyecto de los Dres. Edgardo A. Scotti y Miguel N. Falbo) vino a complementar el régimen establecido en el nuevo artículo 2505 del Código, alejando cualquier tipo de duda sobre el carácter del sistema registral argentino. Ver ANDORNO, Luis O. - MARCOLIN DE ANDORNO, Marta, Ley nacional registral inmobiliaria. Ley 17.801. Comentada. Anotada, Hammurabi, Buenos Aires, 1989 , págs. 35 y 36.

22 Conf. LLAMBÍAS, Jorge Joaquín - ALTERINI, Jorge H., Código Civil Anotado. Doctrina-jurisprudencia, Tomo IV-A, Derechos Reales, Abeledo Perrot, Buenos Aires, 1981, comentario art. 2505, pág. 291. Son "terceros interesados" por ejemplo, los sucesores particulares, la masa del concurso, los titulares de otros derechos reales, los acreedores privilegiados, retentores, quirografarios, o sea, en general los titulares de derechos subjetivos, continúan señalando los juristas citados. Llambías aclara que para él hablar de "tercero interesado" es propio de la teoría del pago, por ello prefiere referirse al tercero “legitimado”. Ver ob. cit., pág. 292.

23 Así, "la registración sólo hace falta para los terceros ‘interesados' (es decir) aquellos que sustentan un derecho que resultará perjudicado a raíz de la mutación... No son terceros interesados los que resultan beneficiados y a los cuales nadie pretende 'oponerles' la mutación...”, ob. cit., pág. 267.

24 Por su parte Llambías y Alterini señalan que "esta concepción del tercero registral es de difícil sustento en nuestro derecho... (es que) sería ir demasiado lejos connotar al tercero con el aditamento tan específico de registral, cuando la ley nada dice.”, conf. LLAMBíAS, Jorge Joaquín - ALTERINI, Jorge H., Código Civil Anotado.ob. cit., pág. 291. López de 
fe" del tercero para poder invocar la inoponibilidad del negocio en cuestión.

Por último, debe remarcarse que lo que se inscribe es el título (instrumento), en nuestro caso la escritura pública. De ello se deduce que no hace falta que el "modo-traditio" se haya verificado en la realidad para poder inscribir el mentado título ${ }^{25}$.

De hecho excede a las facultades calificadoras del Registro corroborar o exigir la realización efectiva de la tradición como requisito a la inscripción.

Por cierto que las fórmulas tantas veces empleadas por los Escribanos en las escrituras en las cuales reproducen las manifestaciones de las partes de haber entregado ya la posesión, carecen de valor legal alguno. Sólo serán válidas cuando el Escribano efectivamente haya estado presente en la toma de la posesión y así lo declare.

Así las cosas, puedo afirmar que del sistema puro ideado por Vélez que representaba la teoría del título y el modo se pasa -desde la mentada modificación al art. 2.505- al sistema del título y modo imperfecto. Ello puesto que sigue inalterado el art. 577 por lo tanto siempre hace falta el requisito de la tradición para constituir o hacer nacer al derecho real en cuestión. Pero para que surta efectos respecto de todos ya se necesita la inscripción del título en el Registro pertinente. Pero para las hipotecas, quepa aclarar, desde el origen del Código rige -y aún sigue intacto- el sistema del consensualismo mitigado ${ }^{26}$.

También merece destacarse que el sistema peruano, en materia de bienes inmuebles, es declarativo. De ello no quepa la menor duda. Si con el solo consensus al parecer ya se opera la transferencia del derecho real sin necesidad de traditio alguna, menos aún será necesaria la inscripción registral con carácter constitutivo del mismo.

Sin embargo, por otro lado, se dota de gran importancia a la mentada inscripción registral. Ello puesto que según mi parecer dicha inscripción tiene carácter convalidante (a diferencia del propio sistema argentino). Y sostengo ello porque el art. 2014 del Código Civil -cuando consagra el principio de buena fe pública registraldetermina que "El tercero que de buena fe adquiere a título oneroso algún derecho de persona que en el registro aparece con facultades para otorgarlo, mantiene su adquisición una vez inscrito su derecho, aunque después se anule, rescinda o resuelva el del otorgante por virtud de causas que no consten en los registros públicos. La buena fe del tercero se presume mientras no se pruebe que conocía la inexactitud del registro".

Precisiones sobre el “DereCho A LA POSESIÓN" (IUS AD POSSESSIONEM), "DERECHO DE LA POSESIÓN" (IUS POSSESSIONIS), Y EL “DERECHO DE POSEER" (IUS POSSIDENDI)

Ya sentado ello, voy a repasar esa relación que existe entre el derecho personal o creditorio, el contrato y el derecho real. Ello puesto que el acreedor solo será dueño cuando se practique la pertinente traditio (conf. art. 577 del Cód. Civ.; y 947 del Código de Perú siempre aludiendo a cosas muebles). Hasta tanto solo goza de un derecho personal. Y lógicamente el deudor, en estos casos tratados, debe hacer la entrega de una cosa cierta para constituir el mentado derecho real. Intentemos comprender ahora esa premisa bajo esta otra óptica que propongo.

Como primera precisión acaso tenga que recordar que, como bien señala el artículo 2468 del Código de Vélez, "Un título vá-

Zavalía comparte el parecer de Padilla al decir que si bien para prevalerse de la inoponibilidad no necesita estar inscripto, pero "para no ser vencido en la litis por otras razones, en múltiples casos, necesitará estar inscripto”, ob. cit., pág. 269. Como vemos la situación da para mucho pero poco es el espacio con el que aquí cuento. Padilla sostiene que al "tercero" hay que exigirle buena fe, título oneroso y registración, ello para lograr la "inoponibilidad" que consiste en la facultad conferida a determinadas personas de evitar que un negocio incida desfavorablemente en su patrimonio en la medida de sus intereses. Es decir que el acto se tiene como válido pero la negociación se entiende no realizada en la medida que le perjudique. En pocas palabras consiste en "la atribución conferida a un tercero de prevalerse de la falta de registración de un derecho real registrable, en tanto lesione su derecho, que tenga registrado", conf. PADILLA, René A., Estudios de Derecho Civil y Registral Inmobiliario, cit., págs. 32 y 40.

25 En este sentido en las VIII Jornadas Nacionales de Derecho Civil, realizadas en La Plata en 1981, se concluyó que “La tradición no es en la actualidad un presupuesto indispensable de la inscripción registral" (Comisión 4, conclusión III).

26 Conf. LÓPEZ DE ZAVALÍA, Fernando, ob. cit., pág. 249. Aclara el querido maestro que el artículo 2.505 supone una mutación ya operada extra-registralmente que se perfecciona después con la inscripción. Es que con el sólo título lo único que hay es un derecho personal. Con el título más la tradición ya hay un derecho real, pero la mutación es "imperfecta". Por último, con el título, más la tradición, más la inscripción (sin importar el orden) ya tendremos una mutación "perfecta”. Ver, LÓPEZ DE ZAVALÍA, Fernando, Curso introductorio..., ob. cit., pág. 255. 
lido no da sino un derecho a la posesión de la cosa, y no la posesión misma". En igual sentido, el último Proyecto (del año 2012) de legislación unificada en Argentina prescribe en su art. 2239 que "Un título válido no da la posesión o tenencia misma, sino un derecho a requerir el poder sobre la cosa. El que no tiene sino un derecho a la posesión o a la tenencia no puede tomarla; debe demandarla por las vías legales"27.

Ello quiere decir que en el sistema legal argentino un título válido, entendido como "causa fuente", solamente dará la posibilidad de que el tradens entregue la posesión -o tenencia-, pero no implica que de hecho ya se la detente. Es más, si voluntariamente la persona obligada a practicar la traditio "posesoria" -o de mera tenencia, o del mismo derecho real- no lo hiciere, hay que recurrir a las vías legales pertinentes para obtener dicha finalidad (vg. acción de cumplimiento contractual).

Esto significa -en pocas palabras- que un título válido en- gendra el derecho a la posesión (ius ad possessionem). Vale decir que los contratos de compraventa, donación, permuta, etc., otorgan el derecho para adquirir la posesión -o tenencia, o dominio, insisto-, pero no la posesión misma hasta tanto no se haga la pertinente traditio. Sin duda que aquí nos movemos en el ámbito exclusivo de los derechos personales, por lo menos afirmado ello respecto del Derecho argentino que siempre pregona la necesidad de operar la tradición de la cosa para hacer nacer al derecho real pertinente.

Y si bien por medio de la regla consagrada en el art. 949 del Código Civil peruano alguien podrá argumentar que el acreedor ya es dueño no obstante no haberse practicado la traditio, yo replicaré que será un dueño bastante "especial", con un derecho real mutilado, pues no tendrá en los hechos las facultades típicas de éste, tales como el ius utendi (derecho de usar la cosa) y ius fruendi (derecho de gozar o disfrutar), precisamente porque carece del pro- pio ius possessionis... Vale decir que tendrá una "propiedad" sin posesión, sin derecho a usar ni probablemente gozar de la cosa. Tampoco se podrá hacer valer frente a todo el mundo si no está debidamente inscripto. ¿Qué clase de derecho real es éste que no es absoluto, ni oponible erga onmes?.

Ahora corresponde tratar mínimamente el denominado derecho de la posesión (ius possessionis). Voy a comenzar recordando que la posesión, desde mi óptica, es principalmente un hecho ${ }^{28}$, un hecho que genera consecuencias jurídicas. Entre las consecuencias jurídicas que engendra este "señorío fáctico" -como diría el querido maestro Fernando López de Zavalía- se encuentran en un primer orden las llamadas acciones posesorias. Dicho ello con carácter general y sin desconocer otras consecuencias relevantes que también derivan de la posesión ${ }^{29}$.

Tampoco voy a entrar en discusiones respecto de la naturaleza jurídica de la posesión conside-

27 Es claro que en la proyectada legislación se prevé la adquisición de la posesión o la "tenencia", siendo más amplia esta solución que incluye expresamente a la tenencia, conclusión a la cual igualmente había llegado la doctrina. Es que lo que se veda es recurrir a la propia fuerza, a las vías de hechos privadas. Por ello debe requerirse el "poder sobre la cosa" a través de las "vías legales", tal como resalto en el texto.

28 Es famosa la polémica -muchas veces sobredimensionada- entre Ihering y Savigny respecto de la naturaleza jurídica de la posesión. El primero sostenía que la posesión era un derecho, específicamente un derecho real. Ello lo deducía de su particular visión acerca del Derecho: al ser la posesión un interés jurídicamente protegido -principalmente mediante las acciones posesorias que tienden a tutelarla-, necesariamente la posesión tiene que ser un derecho. Por su parte Savigny proclamaba que la posesión era un hecho, un hecho que genera consecuencias jurídicas, tal como resalto en el texto. Por cierto que el último Proyecto de Código unificado en su artículo 1909 expresa que "Hay posesión cuando una persona, por sí o por medio de otra, ejerce un poder de hecho sobre una cosa, comportándose como titular de un derecho real, lo sea o no". La negrita me pertenece. Estimo que esta disposición es compatible con la doctrina que sostengo, tal que la posesión es, ante todo, un "hecho", una situación fáctica.

29 Como consecuencias relevantes derivadas de la posesión, o mejor dicho "funciones" de la misma, cabe recordar que: a) en primer lugar la posesión es el contenido de un derecho, "porque es uno de los aspectos más importantes de los derechos reales que se ejercen por la posesión, en cuanto constituye el medio indispensable para realizar todos los fines prácticos de aquellos que, sin la posesión, quedarían vacíos de contenido útil. b) Es requisito para el nacimiento de un derecho. Así, tanto en la tradición (art. 577) como en la prescripción adquisitiva (arts. 3999,4015 y 4016 bis) y en la ocupación (arts. 2525 y 2527), la posesión se presenta como exigencia ineludible a la adquisición de derechos reales. c) Es fundamento de un derecho: La posesión en sí misma, independientemente de que esté respaldada por un título es protegida de toda turbación o privación aun en contra del mismo propietario. Es lo que consagra la primera parte del art. 2469 Código Civil”, conf. René E. PADILLA, Manual de Derechos Reales, tomo I, UNSTA, Tucumán, 2011, pág. 153. La negrita es mía. 
rando cómo está contemplada en el Código Civil vigente del Perú. Allí a primera vista está consagrada como un "derecho real principal", según su ubicación sistemática. Pero si se lee con detenimiento la propia definición legal ${ }^{30}$ puede fácilmente compartirse la tesis que defiendo: que la posesión es, ante todo, una situación fáctica, un poder de hecho que se tiene sobre la cosa.

Por último, corresponde practicar una breve alusión a la tercera figura que tiene incidencia en esta temática. Me refiero al derecho de poseer (ius possidendi) el cual se relaciona con el derecho real. Ello puesto que solo los poseedores que sean titulares de un derecho real, serán aquellos que ostenten dicho ius possidendi. Vale decir que aquellos poseedores que estén en ejercicio de un derecho real legítimamente constituido tienen a su alcance no tan sólo las acciones posesorias sino también, y principalmente, las petitorias (acción reivindicatoria, negatoria, confesoria y de "deslinde" -agregada esta última expresamente en el último Proyecto argentino-).

Conflictos QUE PUEDEN PRESENTARSE CON “TERCEROS” EN EL RÉGIMEN DE LAS OBLIGACIONES DE DAR COSAS CIERTAS PARA TRANSFERIR DERECHOS REALES

No puedo finiquitar esta cuestión fundamental sin hacer una breve mención a ciertos conflictos que pueden presentarse en estas situaciones. Allí se verán en los hechos las distintas consecuencias que traen aparejadas seguir un sistema de constitución de derechos reales, u otro.

Hasta el momento he tratado cuestiones que se limitan a esa relación obligacional que se crea y genera efectos solo entre el deudor y el acreedor. Podría decir que me manejé dentro de los efectos "relativos" que crean las obligaciones.

Ahora vamos a ver entrar en acción otras personas, terceros. Aunque no sea crea qué "tan terceros", pues en puridad los casos que veremos enseguida versan sobre conflictos entre diversos acreedores (y de cada uno de éstos también se puede pregonar los referidos efectos relativos de las obligaciones...). Pues bien, veámoslo.

Por lo pronto los artículos que someramente veremos del ordenamiento argentino obran desde el 592 al 596 del Código Civil. Allí se podrá advertir que las situaciones que trata versan sobre obligaciones de dar cosas ciertas (para transferir o constituir derechos reales) ya sean muebles, ya inmuebles. Respecto del sistema peruano, los artículos del Código Civil en cuestión son dos, a saber: respecto de cosas inmuebles, el 1135 ; y de muebles, el $1136^{31}$.
Siempre tratándose de bienes "ciertos".

Los artículos 592 y 593 del Código Civil argentino se refieren a cosas "muebles". El primero de éstos trata sobre la siguiente situación: cuando el deudor, no obstante tener una obligación anterior con otro sujeto a quien debería hacer la entrega de la cosa mueble para transferir el derecho real, la practica a otra persona. Vale decir que realiza la traditio a otro sujeto (también acreedor a dicha entrega, lógicamente).

En ese caso, cuando el deudor hizo ya la entrega de la cosa, con la finalidad de transferir su dominio (o constitución de prenda), "el acreedor aunque su título sea de fecha anterior, no tendrá derecho contra los poseedores de buena fe, sino solamente contra los de mala fe. La mala fe consiste en el conocimiento de la obligación del deudor" (conf. art. 592 del Cód. Civ. argentino).

Vale decir que este acreedor "defraudado" solo tendrá a su alcance una acción personal, de daños y perjuicios, contra su deudor, siempre y cuando la persona que hubiere recibido la tradición de la cosa sea poseedor de buena fe, sin importar si es de fecha posterior.

Acaso sea conveniente que adelante algo respecto de una regla elemental en materia de dere-

30 Dice el art. 896 del Código de Perú que “La posesión es el ejercicio de hecho de uno o más poderes inherentes a la propiedad". Por cierto que tratar a la posesión antes que los derechos reales (o demás derechos reales, dirán algunos) es acertado, puesto que tanto la posesión cuanto las cosas son los elementos de los derechos reales.

31 Ambos artículos son sustancialmente idénticos que los artículos 1174 y 1173 del Código Civil peruano de 1936, aunque se ha sustituido la expresión "instrumento público" usada por dicho Código por la de "documento de fecha cierta que usa el nuevo como se verá a continuación. Además se ha agregado, por sugerencia a la Comisión Revisora del profesor Felipe Osterling Parodi, la expresión "buena fe", en relación al acreedor que haya inscrito su título, para ser preferido en el caso que contempla el art. 1135 referido a los bienes inmuebles. Ver, precisamente, OSTERLING PARODI, Felipe, Las Obligaciones, Editora Jurídica Grijley, octava edición actualizada, reimpresión, Perú, 2010, pág. 49. 
chos reales, referida a las cosas muebles. Me refiero al art. 2412 del Código Civil argentino, el que dice que "La posesión de buena fe de una cosa mueble, crea, a favor del poseedor, la presunción de tener la propiedad de ella, y el poder de repeler cualquier acción de reivindicación, si la cosa no hubiere sido robada o perdida". ${ }^{32}$

En nuestro caso en especial, aquel contemplado en el art. 592 del Código de Vélez, se puede decir que se hace alguna aplicación de ese principio básico que se resume en el adagio "posesión vale título". Sostengo ello pues tratamos sobre cosa mueble, y se prefiere a su poseedor siempre que sea de buena fe. Es cierto, no es que se presuma la propiedad de la cosa (que de hecho la tiene), sino que será preferido frente a otros acreedores por haberse gestado el derecho real en su cabeza, con la pertinente traditio, sin importar si es de fecha posterior.

En cambio, la situación que contempla el artículo 593 del Cód. Civ. es diversa. En ese caso aún no se hizo efectiva la pertinente traditio y son varios los acreedores que tienen derecho sobre la cosa. Todos para transferir o constituir derechos reales sobre ella, quepa aclarar. Pues bien en esa situación, en la cual ningún acreedor tiene la cosa efectivamente por no haber mediado traditio alguna, "será preferido el acreedor cuyo título sea de fecha anterior", dice la norma comentada.

Es decir que en este segundo supuesto, en el cual no medió entrega alguna, sí se tiene en consideración cuál acreedor es de fecha anterior, para hacerle a él la pertinente traditio posesoria, teniendo mejor derecho que los otros acreedores.

Aquí se hace una aplicación del principio prior in tempore patior in iure, ello puesto que será preferido el acreedor de fecha anterior, aquél que tiene prioridad temporal tendrá mejor derecho. Quepa aclarar que este adagio funciona como un principio residual, operativo cuando no median otras soluciones aplicables a la especie, y siempre que se traten de sujetos que se encuentren en igualdad de condiciones. Allí, entonces, el Derecho prefiere al primero de éstos.

Ahora bien, respecto del ordenamiento peruano las soluciones a aplicar son exactamente las mismas. Vale decir que si se materializó la tradición de la cosa "mueble", y por lo tanto se constituyó el derecho real en cabeza de ese acreedor, va a prevalecer y excluir a los otros acreedores, así cuenten con fecha anterior a la suya. Por supuesto siempre que tenga buena fe, la cual se presume, dicho sea de paso.

En efecto, dice el artículo 1136 del Código peruano de 1984 que "Si el bien que debe entregarse es mueble y lo reclamasen diversos acreedores a quienes el mismo deudor se hubiese obligado a entregarlo, será preferido el acreedor de buena fe a quien el deudor hizo entrega de él, aunque su título sea de fecha posterior".
Vale decir que en este caso la traditio, al funcionar como constitutiva del derecho real, tiene la fuerza suficiente como para excluir a los derechos personales esgrimidos por los otros acreedores defraudados quienes lógicamente tendrán acción de daños y perjuicios (por lo menos) contra su deudor infiel.

En cambio, si no se hubiera concretado la tradición y por lo tanto todos los acreedores gozan solo de derechos personales, ante esta paridad de condiciones será de aplicación la máxima de "primero en el tiempo mejor en el derecho", lo que equivale a premiar al acreedor cuyo título sea de fecha cierta más antigua. En efecto, reza el mismo artículo 1136 que "Si el deudor no hizo tradición del bien, será preferido el acreedor cuyo título sea de fecha anterior; prevaleciendo, en este último caso, el título que conste de documento de fecha cierta más antigua".

Comentando dicha disposición legal, dijo el reconocido profesor Osterling Parodi que "Si se tratara de un bien mueble y lo reclamaran diversos acreedores a quienes el mismo deudor se hubiese obligado a entregarlo, será preferido el acreedor de buena fe a quien el deudor haya hecho tradición del bien, aunque su título sea posterior. Si el deudor no hubiera efectuado la tradición, será preferido el acreedor cuyo título sea de fecha anterior, salvo que el de alguno conste de documento de fecha cierta. El precepto tiene origen en los artículos 1141 del Código Francés, 592 y 593 del

32 En el Código peruano debo transcribir el art. 912 que dice que "El poseedor es reputado propietario, mientras no se pruebe lo contrario. Esta presunción no puede oponerla el poseedor inmediato al poseedor mediato. Tampoco puede oponerse al propietario con derecho inscrito". 
Código Argentino y 1141 del Código Dominicano"33.

Como vemos, las soluciones son prácticamente idénticas en ambos ordenamientos objeto del presente estudio (con pequeños detalles menores, como ser que el Código peruano exige expresamente que se trate de fecha "cierta"), por ello lo que dije respecto del sistema argentino es perfectamente aplicable en el peruano, mutatis mutandi.

Ahora bien, pasemos a las cosas inmuebles. Es claro que -según todo lo antedicho- las soluciones aquí serán distintas, pues se consagran sistemas disímiles en esta materia. Título y modo imperfecto en Argentina. Y consensualismo mitigado en Perú.

Veamos primero lo que ocurre en Argentina. En estos supuestos también debemos tener en consideración si se realizó, o no, la pertinente traditio posesoria. También se resuelve a favor del acreedor que efectivamente tuviere la cosa. Además podría agregar que en estos casos deben mediar escrituras públicas, pues tratamos sobre el régimen de constitución o modificación de derechos reales sobre inmuebles (aunque hay cierta doctrina que también en este caso invita a participar al boleto de compraventa inmobiliaria, problema que por fortuna en el Perú no se presenta).

Así las cosas, dice el artículo 594 del Código Civil argentino que si el deudor hiciere la tradición a "otro acreedor", con el fin de transferirle el dominio, "el acreedor no tendrá derecho contra tercero que hubiese ignorado la obligación precedente de su deudor; pero sí contra los que sabiéndola hubiesen tomado posesión de la cosa".

Como puede advertirse en este caso en especial tampoco se tiene en consideración si el acreedor que ha recibido la cosa es de fecha posterior. De hecho lo es, por ello habla que la buena fe consiste en no haber tomado conocimiento de la obligación "precedente" del deudor. Otra vez se prefiere y protege al que recibió la cosa, el único que se podrá pregonar y sentirse verdadero "dueño".

Recordé otra vez la preeminencia que tienen los derechos reales por sobre los personales. Aquí simplemente se aplica esa directiva. El acreedor que recibió la cosa es el dueño de la misma (conf. art. 577 del Cód. Civ. argentino) y por ello, siempre que tenga buena fe y que su título haya tenido verdadera vocación real, resultará vencedor frente a otros acreedores, incluso y principalmente si son de fecha anterior.

Claro que la situación no queda allí. Estamos hablando de un acreedor defraudado. Pero éste no puede "agredir" al que recibió la cosa, siempre que tenga buena fe y los demás recaudos que ya señalé. Entonces tendrá que accionar contra su deudor, frente a quien le podrá exigir "otra cosa equivalente, y todos los perjuicios e intereses", dice el artículo 595 del Código Civil de Vélez.
Finiquitando con el ordenamiento argentino, también trata Vélez la situación en la cual concurren varios acreedores frente a quienes el mismo deudor se hubiere obligado a realizar la entrega de la cosa "inmueble", sin haber practicado aún la traditio a ninguno de éstos. Aquí también la solución es que será preferido aquel acreedor cuyo título sea de fecha anterior. Quepa agregar que en esta solución en especial se pide expresamente que se trate de un instrumento público aquel título de fecha anterior, por lo tanto no podrá un boleto de compraventa privado competir contra una escritura pública en estas situaciones.

El artículo en cuestión es el 596 del Código Civil, el que reza "Si la cosa fuere inmueble, y concurriesen diversos acreedores a quienes el mismo deudor se hubiese obligado a entregarla, sin que a ninguno de ellos le hubiese hecho tradición de la cosa, será preferido el acreedor cuyo instrumento público sea de fecha anterior".

Lo mismo que dijimos con respecto a las cosas muebles, en cuanto a la aplicación de la regla prior in tempore patior in iure, aquí puedo reiterar, mutatis mutandi.

Ahora bien, pasemos al sistema de cosas inmuebles en el ordenamiento peruano. Tantas veces remarqué que en este tema se sigue la teoría del consensualismo mitigado, pues el acreedor de una cosa inmueble cierta es considerado propietario des-

33 OSTERLING PARODI, Felipe, Las Obligaciones, Editora Jurídica Grijley, octava edición actualizada, reimpresión, Perú, 2010, pág. 51. 
de la misma celebración del contrato. Ello implica seguir el sistema consensualista. Y es mitigado pues se requiere la pertinente inscripción de la escritura pública en el registro para logar plena oponibilidad del derecho en cuestión.

Así las cosas, es lógico que el legislador peruano no tuviera en cuenta si se realizó o no la traditio para resolver los conflictos que se pueden presentar, cuando varios acreedores concurren frente a un bien en común vendido por el mismo deudor.

Y siendo que la traditio posesoria no es constitutiva del derecho real inmobiliario, la solución brindada en el ordenamiento peruano tiene en vista a la inscripción registral. Por ello el acreedor que primeramente haya llegado al registro va a ser el preferido, siempre y cuando tenga buena $\mathrm{fe}^{34}$, claro está.

Solo en defecto de inscripción registral, lo que equivale a sostener que ningún acreedor ha inscripto su derecho (lo que revela igual grado de negligencia en todos), va a ser premiado el de fecha anterior, el de fecha cierta más antigua, haciendo otra vez aplicación a aquel prin- cipio residual de "primero en el tiempo mejor en el derecho".

En efecto, dice el art. 1135 del Código Civil de Perú que "Cuando el bien es inmueble y concurrieren diversos acreedores a quienes el mismo deudor se ha obligado a entregarlo, se prefiere al acreedor de buena fe cuyo título ha sido primeramente inscrito $o$, en defecto de inscripción, al acreedor cuyo título sea de fecha cierta anterior. Se prefiere, en este último caso, el título que conste de documento de fecha cierta más antigua".

En suma, como claramente señala Osterling Parodi, "el principio de preferencia para los inmuebles opera a favor de aquel acreedor de buena fe cuyo título haya sido inscrito y para los bienes muebles, a favor de aquel acreedor de buena fe a quien el deudor haya hecho tradición del bien. En ambos casos se exige que el acreedor proceda de buena fe, es decir sin conocer la existencia de obligaciones previas, pues la ley tiene el sentido moral de proteger la lealtad con que se contrata. Si en el primer caso el título no hubiera sido inscrito, o en el segundo el vendedor no hubiera hecho tradición del bien, entonces se preferirá -para ambos casos- al acreedor cuyo título sea de fecha anterior, salvo que el de alguno conste de documento de fecha cierta. Estas normas son idóneas y protegen adecuadamente, dentro del relativismo que prevalece en esta materia, los derechos de los intervinientes en una relación obligacional"35.

Para finiquitar con el sistema peruano haré un breve análisis final.

\section{Conclusiones finales REFERIDAS AL SISTEMA PERUANO ACTUAL}

Según lo escrito ut supra puedo llegar a estas breves conclusiones referidas exclusivamente al sistema que rige en Perú desde el año 1984, a saber:

En materia inmobiliaria, se opta por el sistema francés del consensualismo, puesto que basta el solo consensus para hacer adquirir el derecho real en cuestión, por lo que se prescinde de la tradición como medio constitutivo -art. 949 del Cód. Civil-.

Respecto de bienes "muebles" sí se requiere la pertinente traditio posesoria para que sea

34 Se ha agregado el requisito de "buena fe" en forma expresa para evitar toda clase de controversias al respecto. Al respecto se ha afirmado que "es principio elemental que la garantía de los Registros no ampara ni puede amparar a la mala fe. Inclusive aquellas legislaciones como la alemana y la suiza, que dan al Registro alcances mucho mayores que los que tiene en el Perú, consideran a la mala fe como causal de pérdida de la garantía que otorgan" (conf. Exposición de Motivos del Reglamento General de los Registros Públicos).

35 OSTERLING PARODI, Felipe, Las Obligaciones, Editora Jurídica Grijley, octava edición actualizada, reimpresión, Perú, 2010, págs. 51 y 52. Continúa allí el destacado jurista diciendo que "En el caso de los bienes inmuebles, y si se tratara de la transferencia del dominio, el acreedor preferido, al haber adquirido la propiedad, podrá ejercitar la acción reivindicatoria para exigir la entrega. En hipótesis similar, y tratándose de bienes muebles, si el acreedor hubiera sido puesto de mala fe en posesión del bien, el acreedor preferido no podrá promover exitosamente la acción reivindicatoria porque ella nace del dominio, que no habría sido adquirido, precisamente, por la falta de tradición. En este último caso la acción procedente sería la revocatoria o pauliana. El acreedor de buena fe burlado, podría ejercer, adicionalmente, acción indemnizatoria contra el deudor y el acreedor de mala fe". Es importante que resalte que aquí, justamente, radica una de las consecuencias prácticas de seguir un sistema de constitución de derechos reales, u otro. Como se nota con claridad, Perú ha seguido dos distintos, uno para cosas muebles (que requieren de la tradición) y otro para los inmuebles (en donde basta el solo consensus). De allí que el acreedor de un bien inmueble pueda promover la acción reivindicatoria por haberse operado la transferencia de dominio a su favor, remedio que el acreedor de cosa mueble no tiene a su alcance. 
considerado dueño el acreedor de la cosa en cuestión (art. 947 del Cód. Civ.).

Se puede afirmar que se consagra un doble sistema: del consentimiento mitigado, (estilo francés), para los bienes inmuebles; y del título y modo (estilo romano) para los muebles.

Además me animo a sostener que no obstante que a simple vista pareciera ser innecesaria la tradición y la propia inscripción registral, en cuestiones inmobiliarias, ello no es tan cierto puesto que existen ciertas ventajas evidentes a favor de quienes ostenten la posesión real de la cosa y quienes inscriban su derecho en el Registro inmobiliario.

Para empezar debo recordar que el poseedor es reputado propie- tario (resultando dicha presunción muy práctica) y en tanto que poseedor tiene a su alcance todas las defensas que hacen a la posesión misma. Claro que esta presunción de propiedad de la que goza el poseedor no puede oponerla "al propietario con derecho inscrito", dice el art. 912 del Código Civil ${ }^{36}$.

Por otro lado y respecto del ámbito registral, el que hubiere acudido al Registro, y tenga buena fe y título oneroso, mantiene su adquisición una vez inscrito su derecho "aunque después se anule, rescinda o resuelva el del otorgante" (conf. art. 2014 del Cód. Civ.).

Amén de ello, puede "oponer" su derecho real inscripto a quien no lo hubiere hecho aún o lo haga con posterioridad (art. 2022 del Cód. Civ.).
Además, si acaso el vendedor o deudor se ha obligado a entregar el bien inmueble a varios acreedores, como vimos, va a ser preferido aquel acreedor de buena fe que haya acudido en primer término al Registro a inscribir su título (conf. art. 1035 del Cód. Civ.).

Así las cosas me pregunto ¿qué tan facultativa es la inscripción registral en materia inmobiliaria en el sistema peruano, tal como lo sostiene, livianamente, alguna jurisprudencia ${ }^{37}$ ?

Ahora sí estoy en condiciones de terminar este breve trabajo esperando que sirva para entender mínimamente las relaciones que existen entre materias que por razones obvias se estudian en distintos ciclos. Acaso tenga que recordar que en definitiva el derecho es uno solo.

36 Acertadamente se ha resuelto que "El art. $912^{\circ}$ del Código Civil ha establecido en beneficio del poseedor la presunción iuris tantum que lo tiene por propietario; sin embargo, el propio art. $912^{\circ}$ dispone que tal presunción no puede ser opuesta al propietario con derecho inscrito, quien más bien, con tal situación publicita su derecho y puede oponerla a los demás", Cas. № 282-96-Ica, El Peruano, 10-06-1998, pág. 1269.

37 Así, se dijo que "En el caso de autos al tratarse de traslación de dominio la Inscripción en los Registros Públicos es facultativa y no obligatoria...”; Cas. № 2328-02- San Román, del 31-04-2004, Revista Peruana de Jurisprudencia, Año 6, 2004, № 38, pág. 238. 